the limbs, and the loss of equilibration became so extreme that he could not remain in a sitting position, invariably falling backward, although the muscular power remained good. Incontinence of the sphincters appeared and persisted after about two weeks.

Postmortem.-At necropsy the pathologic condition found was syphilitic cerebrospinal meningitis, which was especially marked at the base of the brain where the new tissue formation had caused thickening in the pia-arachnoid and complete occlusion of the foramen of Magendie. All of the ventricles of the brain were much dilated, but especially the fourth, where the distention had caused compression of the white matter of both cerebellar hemispheres, and displacement and compression of the dentate nuclei in a symmetrical manner. No gross lesions of any other character were present. That the foramen of Magendie was impervious was demonstrated by removing the pons, medulla and cerebellum from the cerebrum by an incision through the cerebral peduncles, and filling the fourth ventricle via the aqueduct of Sylvius with a solution of eosin; the specimen was then dissected and it was found that none of the stain had penetrated beyond the cavity of the ventricle. Microscopically, the usual changes of cerebrospinal syphilis were present in the meninges and blood vessels of the brain and cord, and in addition, degeneration of many of the cells in the dentate nuclei of both sides, and degeneration, even disappearance in places, of some of the cells of Purkinje in the cerebellar cortex. The distention of the fourth ventricle in this

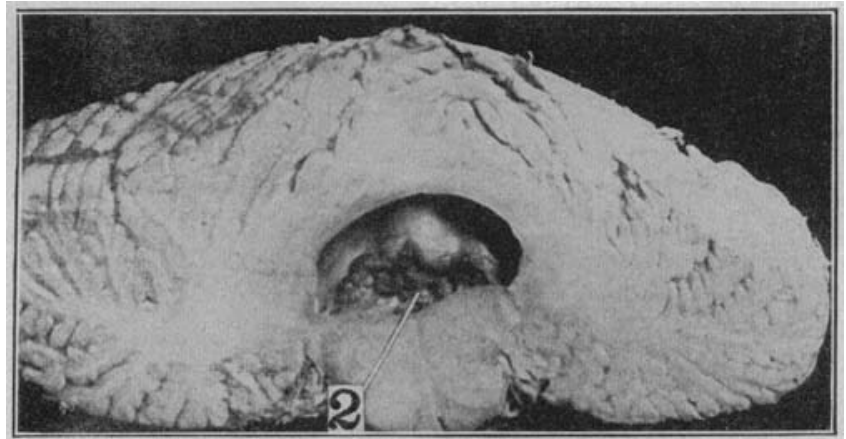

Fig. 3.--Scction through the cerebellum and the medulla showing the matted condition $(2)$ of the choroid plexus at the site of the occhuded foramen of Magendie.

case evidently acted as a symmetrical bilateral lesion involving both dentate nuclei and vermis and accounts for the purely backward type of cerebellar incoordination.

5249 Spruce Street.

The Prevalence of Fleas on Rats and Squirrels.-Previous observations made under government auspices have shown the occurrence of plague in the ground squirrel. The conveyance of plague from rodent to rodent by means of the flea has been proved and it has been shown that the fleas that ordinarily infest rats and also those infesting squirrels will bite man. The possibility of the agency of the ground squirrel in spreading the plague to man is therefore shown. G. W. McCoy and M. B. Mitzmain, in Public Health Reports, July 16, 1909, give the results of further investigations in this direction. Rats and squirrels were combed to determine the varieties and averace number of fleas which they harbor. While the large majority of fleas are found associated with their proper hosts, it was found that rat fleas oceasionally infest squirrels, and vice versa. It has been shown that the rat will live in perfect harmony with squirrels in captivity. The average number of fleas found on a rat varied from 4.7 in one series to 7.6 in another. Live ground squirrels yielded a larger average, 34. Mice, rabbits, skunks and other similar animals were also found to be infested. The nests of rats were found to harbor more fieas than the animals themselves. By placing rats in eages with squirrels, and vice versa, it was shown that an interchange of fieas took place, indicating that fleas from rodents readily adapt themselves to hosts of different species.

\section{OLIVE-POINT SOUND USED AS AN OB'TURATOR}

\section{J. E. TUCKERMAN, M.D. CLEVELAND, 0 .}

Some four or five years ago, while his own physician was away, a man who had always worn a tiacheotomy tube came to me to have the same replaced. The tube had been out some days and the opening was contracted from side to side. On trying to replace it, the tube acted much like a reamer or corer, and would not slip in without paring the edges of the opening. Resort to the makeshift shown in the illustration made the introduction easy. The matter passed entirely from mind until recently my brother, Dr. W. H. Tuckerman, had a like difficulty in introducing a tube, larger than the one

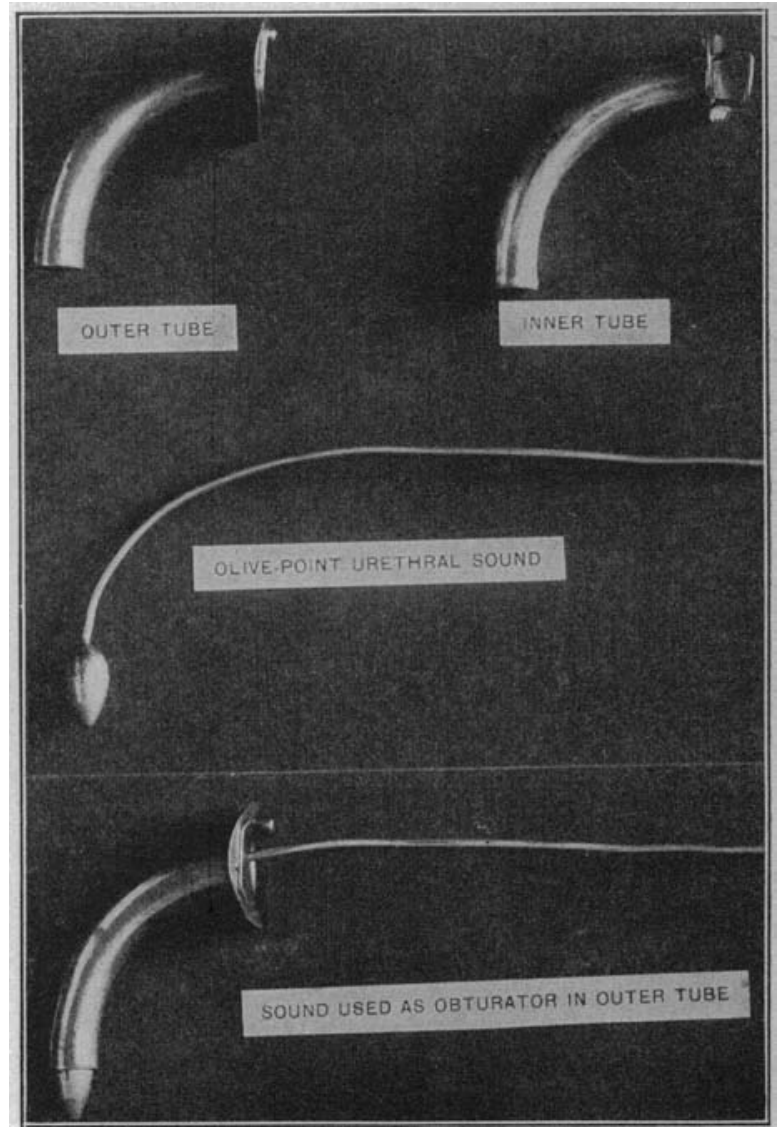

An improvised obturator to facilitate introduction of tracheotomy tube.

being worn, into the trachea of a growing child who has constantly to wear a tube. Again the device shown made the procedure easy.

An obturator might very well be a part of every tracheotomy tube. A tip could be made with a shoulder to fit the inner tube which could then act as an obturator during the introduction of the outer tube. Withdrawal of the inner tube and removal of the tip would then allow the inner tube, when replaced, to fulfill its usual office. No doubt the same or like makeshift has been used by others. Still, even though tracheotomy is not now the common operation it once was, the accompanying illustration may be of interest and perhaps will lead some instrument maker to design a complete tracheotomy tube.

1856 Central Avenue. S.-E. 